\title{
What the investors need to know about forecasting oil futures return
} volatility

\author{
Yudong Wang ${ }^{\mathrm{a}}, \mathrm{Li} \mathrm{Liu}^{\mathrm{b},{ }^{\mathrm{c}}, *}$, Feng Ma $^{\mathrm{d}}$, Chongfeng Wu ${ }^{\mathrm{e}}$ \\ ${ }^{a}$ School of Economics and Management, Nanjing University of Science and \\ Technology, Nanjing, China \\ ${ }^{\mathrm{b}}$ School of Finance, Nanjing Audit University, Nanjing, China \\ c Jiangsu key laboratory of financial engineering, Nanjing Audit University, Nanjing,
} China

${ }^{\mathrm{d}}$ School of Economics and Management, Southwest Jiao Tong University, Chengdu, China

${ }^{\mathrm{e}}$ Antai College of Economics and Management, Shanghai Jiao Tong University, Shanghai, China *Corresponding author

Corresponding address: West Yushan Road 86, Pukou District 210000, Nanjing, China

E-mail: wangyudongnj@126.com (Yudong Wang), liuli840821@126.com (Li Liu) Tel: +86 13611582191 (Li Liu), +86 13681663442 (Yudong Wang) 


\begin{abstract}
In this paper, we evaluate the usefulness of GARCH-class models in forecasting densities of crude oil futures from an investor perspective. Volatility forecasts are taken as the key inputs in calculating predictive densities. We find that FIEGARCH accommodating both long memory and asymmetric effect provides more accurate density forecasts than the other GARCH-class models most of time. GARCH-based dynamic trading strategies perform significantly better than the benchmark of the static strategy even after accounting for the transaction cost. The gains of utility of GARCH-based strategies over the benchmark strategy are as high as 18\%-20\% p.a..
\end{abstract}

Keywords: Crude oil; Futures; Density; GARCH; Portfolio

JEL Classifications: G11, G17, Q47, E37 


\section{Introduction}

Over the last decade, commodity futures have become a popular asset class for portfolio investors, just like stocks and bonds ${ }^{1}$. Crude oil futures are traded actively in the NYMEX. Oil futures price is assigned to the highest weight in constructing some popular commodity price indices such as S\&P Goldman Sachs Commodity Index (GSCI) and the Dow-Jones UBS Commodity Index (DJ-UBS). Moreover, the important effects of oil price shocks on the real economy and financial markets have been well documented in the literature (Baumeister and Peersman, 2013; Jones and Kaul, 1996; Kilian, 2009; Kilian and Park, 2009; Sadorsky, 1999; Wang et al., 2013). Thus, it is not surprising that there are a considerable number of studies on modeling and forecasting oil return volatility.

In the literature, the application of the family of Autoregressive Conditional Heteroskedasticity (ARCH) model (Engle, 1982; Bollerslev, 1986) is the most popular. For example, Sardorsky (2006) finds that some more complex models like state space and bivariate GARCH do not perform as well as the simple univariate GARCH in forecasting oil return volatility. Since then, more sophisticated GARCH-class models are employed to obtain more accurate volatility forecasts. Kang et al.(2009) find that the component GARCH (CGARCH) and fractionally integrated GARCH (FIGARCH) can result in more accurate volatility forecasts. Nomikos and Pouliasis (2011)'s out-of-sample findings show the superiority of Markov Regime Switching GARCH (MRS-GARCH) over conventional ones. More recently, Arouri et al.(2012) show that

\footnotetext{
${ }^{1}$ This was sometimes referred to the financialization of commodity markets (Tang and Xiong, 2012; Cheng and Xiong, 2013).
} 
volatility models accommodating structural breaks and long memory provide the best volatility forecasts for most cases. Hou and Suardi (2012) claim that a nonparametric GARCH yields superior forecasting performance relative to several parametric GARCH-class models. Chkili et al.(2014) find that nonlinear GARCH models allowing for asymmetry and long memory can outperform other GARCH-class models. The out-of-sample results in Kang and Yoon (2013) and Wei et al. (2010) indicate that none of a single model can beat all the other ones. The applications of GARCH models to oil return can also be seen in some other excellent studies (see, e.g., Agnolucci, 2009; Chang, 2012; Fan et al., 2008; Mahringer and Prokopczuk, 2015; Narayan and Narayan, 2007; Wang and Wu, 2012; Youssef et al., 2015). Overall, researchers have done comprehensive studies on forecasting oil market volatility using GARCH models but there is no consensus on which model performs best.

In this paper, we investigate the predictability of oil return volatility from the perspective of a futures investor that is different from most of existing studies. We evaluate the usefulness of volatility forecasts by investigating whether they can improve the accuracy of density forecast. Measuring the accuracy of density forecast rather than volatility forecast is motivated by two issues related to investors. The first issue is that the actual volatility is unobserved for investors. The common method used in the literature for evaluating the forecasting performance is to employ a so-called loss function ${ }^{2}$ which can quantify how far the volatility forecast is from the true one (see, e.g., Wang and $\mathrm{Wu}, 2012$; Wei et al., 2010). Correctly assessing the

\footnotetext{
${ }^{2}$ For the additional discussion on the volatility loss function, one can see Bollerslev et al.(1994).
} 
accuracy of point forecast is not easy because the investors do not know the true volatility. As an outstanding advantage, evaluation of density forecast accuracy does not require true densities, making the results more reliable. The second issue is that market investors pay more attention to the trade-off between return and volatility than to the volatility only. The reason is that return and volatility forecasts are of equal importance in portfolio asset allocation. In recent years, investing in commodity futures is increasingly appreciated for financial investors (Hong and Yogo, 2012; Gorton et al., 2013). In addition, some certain aspects of the densities, such as value at risk, are required by the booming area of risk management (see, e.g., Aloui and Mabrouk, 2010). Evaluating the forecasting accuracy of mean and volatility within a single density forecasting framework is more useful for investors. Thus, the density forecast of return is of greater interest for investors than the point forecast of return volatility.

We apply volatility models to the innovations drawn from the same mean equation, $\mathrm{AR}(1)$. The mean forecast and various volatility forecasts from different models are used to construct density forecasts. Since the mean forecast is consistent, the accuracy of density forecast is actually determined by the volatility prediction. We compare the relative performances of density forecasts using two criteria, average logarithmic score $(\ln S)$ and failure rate (FR). A higher $\ln S$ implies that the corresponding model on average gives higher probability to events that have actually occurred. FR quantifies how often one model fails to beat the benchmark model in density forecasting. Based on these criteria, one can assess the density forecast 
accuracy in the statistical sense without knowing the true density.

To the best of our knowledge, there is very few of studies on density forecasts of oil returns except some notable papers (Ielpo and Sevi, 2013; Lombardi and Ravazzolo, 2012; Høg and Tsiaras, 2011). As an improvement over these related studies, we use more complex GARCH-type volatility models which accommodate some stylized facts of oil return volatility such as asymmetry, long memory and fat-tail distribution. The greater distinction between this paper and existing studies is that we dig out the economic value of density forecasts. We consider an investor with mean-variance utility who allocates his or her wealth between crude oil futures and Treasury bill. The weight of oil futures in this investor's portfolio is ex-ante adjusted every week based on the density forecast. We use the Sharpe ratio and certainty equivalent return (CER) to evaluate the performance of a portfolio. A portfolio with greater performance implies that the corresponding density forecasts are better and therefore the volatility forecasts are more useful for investors as mean forecasts are controlled. As far as we know, there have been no studies that evaluate the usefulness of density forecast or volatility forecast of crude oil return from the dimension of portfolio management.

To start with, we collect weekly price data of crude oil futures contracts with four different maturities, covering a sample period longer than 30 years from January 4, 1985 to June 5, 2015. A rolling window method is employed to do forecasting exercise. We compare the predictive ability of 9 GARCH-class models which consider different kinds of "stylized facts". 
We find that the average logarithmic score $(\ln S)$ of density forecasts of FIEGARCH allowing for both long memory and asymmetric effect is higher than its competitors, and their differences are highly significant according to a statistical test of Mitchell and Hall (2005). This result indicates that FIEGARCH statistically performs better than the other GARCH-class models based on the criterion of $\operatorname{lnS}$. According to the FR criterion, we find that the probability that FIEGARCH beats each of its competitors is significantly higher than 0.5 , a probability of tossing a coin. Moreover, based on a test of Broock et al.(1996), we reject the null hypothesis that the event that FIEGARCH produces better density forecasts occurred independently. These findings suggest that FIEGARCH can result in more accurate density forecasts than each of the other GARCH-class models most of time.

On the economic value of volatility forecasts, our out-of-sample findings indicate that portfolios implied by each GARCH-class models display positive Sharpe ratios. According to the definition of Sharpe ratio, we can say that one can on average obtain positive excess returns by investing in crude oil futures. More importantly, GARCH models can result in the portfolios with higher Sharpe ratios and CER than the benchmark of a static trading strategy which uses a constant weight of individual assets. Therefore, the density forecasts of GARCH-class models have higher economic value than the benchmark strategy. Overall, we can conclude that GARCH-class models display good out-of-sample performances from the perspective of investors.

The remainder of this paper is organized as follows: Section 2 briefly describes 
the volatility model used in our forecasting analysis. Section 3 is data description and gives some preliminary analysis. Section 4 shows main forecasting results. The last section concludes.

\section{Econometric models}

In this paper, we focus on the forecasting performances of popular GARCH-class models. Unlike previous studies which consider the point forecast of return volatility, we evaluate the performance in forecasting return density. As the conditional mean and volatility are needed for constructing density, we first capture the conditional mean using the simple $\mathrm{AR}(1)$ specification $^{3}$ and then employ different volatility models to capture the dynamics of conditional volatility. Because we use the same mean equation in all cases, the accuracy of density forecast is actually determined by the volatility forecast of different models. The use of $\mathrm{AR}(1)$ is motivated by the fact that oil price returns display significant autocorrelations (see, e.g., Wang and Liu, 2010; Wang and $\mathrm{Wu}, 2013)$. The AR(1) model is given by,

$$
r_{t}=\mu+\lambda r_{t-1}+\varepsilon_{t}=\mu+\lambda r_{t-1}+\sigma_{t} z_{t}
$$

where $r_{t}$ is the return of crude oil futures, $z_{t}$ is the standardized residuals which are assumed to be independent. It has been shown in the literature that some occasional events can lead to extreme fluctuations in oil prices which are important sources of fat-tail distribution (Wang and $\mathrm{Wu}, 2012$; Wang et al., 2011). To take into account the fat-tail distribution in oil returns, we use the skew-t distribution of Hansen (1994) with the following density function:

\footnotetext{
${ }^{3}$ In the next section, we will show that oil futures returns display significant serial correlation. This is the motivation why we use AR(1) to model conditional mean of oil futures returns.
} 


$$
g(z \mid \eta, \lambda)=\left\{\begin{array}{l}
b c\left(1+\frac{1}{\eta-2}\left(\frac{b z+a}{1-\lambda}\right)^{2}\right)^{-(\eta+1) / 2}, z<-a / b, \\
b c\left(1+\frac{1}{\eta-2}\left(\frac{b z+a}{1+\lambda}\right)^{2}\right)^{-(\eta+1) / 2}, z \geq-a / b,
\end{array}\right.
$$

where $2<\eta<\infty$, and $-1<\lambda<1$. The constants $a, b$, and $c$ are given by,

$$
a=4 \lambda c\left(\frac{\eta-2}{\eta-1}\right), b^{2}=1+3 \lambda^{2}-a^{2}, \text { and } c=\frac{\Gamma\left(\frac{\eta+1}{2}\right)}{\sqrt{\pi(\eta-2)} \Gamma\left(\frac{\eta}{2}\right)} .
$$

Hansen (1994) shows that this density function has a mean of zero and a unit variance.

Skew-t distribution is equivalent to the traditional student's $t$ distribution when $\lambda=0$.

Based on the return innovations generated by above AR(1) model, we use different models to capture and forecast volatility. Following the pioneering work of Engle (1982), the most popular volatility model is the GARCH proposed by Bollerslev (1986). The standard $\operatorname{GARCH}(1,1)$ is given by ${ }^{4}$,

$$
\sigma_{t}^{2}=\omega+\alpha \varepsilon_{t-1}^{2}+\beta \sigma_{t-1}^{2}
$$

where $\sigma_{t}^{2}$ is the conditional volatility with the sufficient conditions $\omega>0, \alpha \geq 0$ and $\beta \geq 0$ to gauge $\sigma_{t}^{2}>0$. The sufficient conditions for the existence of second moment for GARCH is $\alpha+\beta<1$.

In some empirical studies, it is found that $\alpha+\beta$ is close to unity, implying the infinite volatility persistence (see, e.g., Wei et al., 2010). Engle and Bollerslev (1986) develop a special case of GARCH, named integrated GARCH (IGARCH), that can

\footnotetext{
${ }^{4}$ It may be argued that more lags should be used in GARCH. We use GARCH(1,1) due to two considerations. First, Hansen and Lunde (2005) show that a GARCH model with longer lag lengths cannot significantly beat the simple GARCH $(1,1)$ in forecasting return volatility. Second, the use of more lags will bring much higher calculation burden and takes much more time in computing out-of-sample forecasts.
} 
capture infinite persistence by using the restriction $\alpha+\beta=1$. We will also use IGARCH to model and forecast crude oil return volatility.

An extension of the GARCH is Glosten et al.(1993) GJR-GARCH model that can capture the asymmetric relationships between return and volatility (i.e., leverage effect). The specification of GJR is given by,

$$
\sigma_{t}^{2}=\omega+\left[\alpha+\gamma I\left(\varepsilon_{t-1}<0\right)\right] \varepsilon_{t-1}^{2}+\beta \sigma_{t-1}^{2}
$$

where $I($.$) is an indicator function; i.e., when the condition in the parenthesis is$ satisfied, it takes the value of 1 and 0 otherwise. The parameter $\gamma$ describes the volatility leverage effect. The sufficient condition of GJR is $\omega>0, \alpha \geq 0, \beta \geq 0$ and $\alpha+\gamma \geq 0$ to ensure conditional volatility $\sigma_{t}^{2}>0$. The sufficient condition for the existence of second moment for GJR is $\alpha+\beta+\gamma / 2>0$.

Another GARCH-type model allowing for leverage effect is the exponential GARCH (EGARCH) developed by Nelson (1991). Nelson (1991) points out that the non-negative parameter restriction of GARCH is too strict. EGARCH can address this problem by modeling the dynamics of logarithmic conditional volatility. The volatility equation of GARCH can be written as follows:

$$
\log \left(\sigma_{t}^{2}\right)=\omega+\alpha\left(\left|z_{t-1}\right|-E\left|z_{t-1}\right|\right)+\gamma \mathrm{z}_{t-1}+\beta \log \left(\sigma_{t-1}^{2}\right)
$$

where again the parameter $\gamma$ describes the volatility leverage effect.

The third model with leverage effect that we use to forecast volatility is the asymmetric power ARCH (APARCH) proposed by Ding et al. (1993). This model nests several GARCH-class models as special cases and has been found to perform well in forecasting oil return volatility in some studies (Mohammadi and $\mathrm{Su}, 2010$; 
Giot and Laurent, 2003). The APARCH(1,1) model is given by,

$$
\sigma_{t}^{\delta}=\omega+\alpha\left(\left|\varepsilon_{t-1}\right|-\gamma \varepsilon_{t-1}\right)^{\delta}+\beta \sigma_{t-1}^{\delta},
$$

where the parameter $\delta(\delta>0)$ plays the role of a Box-Cox transformation of standard deviation. The role of leverage effect is reflected by $\gamma$. APARCH nests GJR as a special case when $\delta=2$ and GARCH when $\delta=2$ and $\gamma=0$.

Aforementioned GARCH processes assume the short memory of autocorrelations. That is, the autocorrelations of volatility decay at exponential rates when the lag order increases. This assumption is not consistent with the stylized fact of long memory in financial market volatility (Cont, 2001). Long memory in oil return volatility has also been confirmed in recent studies (see, e.g., Tabak and Cajueiro, 2007; Wang and $\mathrm{Wu}, 2013)$. In order to capture long memory in return volatility, Baillie et al.(1996) propose a fractionally integrated ARCH (FIGARCH). This model implies the hyperbolic decay of volatility autocorrelation, i.e., long memory behavior and the slow rate of decay after a volatility shock. The FIGARCG(1,d,1) process is given by,

$$
\sigma_{t}^{2}=\omega+\beta \sigma_{t-1}^{2}+\left[1-(1-\beta L)^{-1}(1-\varphi L)(1-L)^{d}\right] \varepsilon_{t}^{2},
$$

where $0 \leq d \leq 1, \omega>0, \varphi, \beta<1 ; d$ is the fractional integration parameter and $L$ is the lag operator. An advantage of FIGARCH is that for $0<d<1$, it is sufficiently flexible to consider the intermediate range of the degree of persistence, between the infinite persistence associated with $d=1$ and the geometric decay associated with $d=0$.

Another GARCH-class model allowing for long memory used in this paper is the hyperbolic GARCH (HYGARCH) developed by Davidson (2004). The application of 
HYGARCH to financial returns can be seen in Wei et al. (2010). The HYGARCH specification is given by,

$$
\sigma_{t}^{2}=\omega+\left\{1-[1-\beta L]^{-1} \varphi L\left\{1+k\left[(1-L)^{d}-1\right]\right\}\right\} \varepsilon_{t}^{2},
$$

where $0 \leq d \leq 1, \omega>0, k \geq 0, \varphi, \beta<1 . L$ is the lag operator. We can see that HYGARCH process corresponds to FIGARCH for $k=1$ and stable GARCH for $k=0$.

We also consider two popular models accommodating both long memory and asymmetric effect. The first is the FIEGARCH $(1, \mathrm{~d}, 1)$ of Bollerslev and Mikkelsen (1996) which is given by,

$$
h_{t}=\left(1-L^{d}\right)\left(\ln \sigma_{t}^{2}-\omega\right)=\beta h_{t-1}+g\left(z_{t-1}\right)+\varphi g\left(z_{t-2}\right),
$$

where $g\left(z_{t}\right)=\theta z_{t}+\gamma\left(\left|z_{t}\right|-E\left|z_{t}\right|\right)$.

The second is the FIAPARCH of Tse (1998) which is given by,

$$
\sigma_{t}^{\delta}=\omega(1-\beta)^{-1}+\left[1-(1-\beta L)^{-1}(1-\varphi L)(1-L)^{d}\right]\left(\left|\varepsilon_{t}\right|-\gamma \varepsilon_{t}\right)^{\delta},
$$

The applications of FIAPARCH to oil market data can be seen in some recent studies (see, e.g., Aloui and Mabrouk, 2010; Chkili et al., 2014).

In summary, we will employ 9 GARCH-class models, GARCH, IGARCH, GJR, EGARCH, APARCH, FIGARCH, FIEGARCH, FIAPARCH and HYGARCH to describe and forecast volatility.

\section{Data and preliminary analysis}

We use the weekly price data of crude oil futures covering the period from January 4, 1985 to June 5, 2015, resulting in 1588 observations $^{5}$. We consider four futures contracts with different maturities traded in NYMEX. Contract 1 is a futures

\footnotetext{
${ }^{5}$ We do not use daily data because it is less possible to rebalance portfolio everyday due to the effect of transaction cost.
} 
contract specifying the earliest delivery date. For crude oil, each contract expires on the third business day prior to the 25th calendar day of the month preceding the delivery month. If the 25th calendar day of the month is a non-business day, trading ceases on the third business day prior to the business day preceding the 25 th calendar day. After a contract expires, Contract 1 for the remainder of that calendar month is the second following month. Contracts 2-4 represent the successive delivery months following Contract 1 .

The selection of futures contracts is motivated by the fact that the short-term futures contracts are traded much more actively than long-term contracts. As the evidence, Alquist and Kilian (2010) shows that trading volume of 1-month futures contracts is 10 times higher than volume of 6-month futures contracts. The trading volume of 1-year contracts is even close to zero sometimes. High liquidity of short-term contracts ensures that dynamic trading strategy can be completed by re-balancing portfolio frequently. Therefore, we choose short-term futures contracts with maturity of $1,2,3$ and 4 months to check whether the usefulness of GARCH-based trading strategy is robust for different futures maturities. Figure 1 shows the graphical illustration of oil futures prices. All price data are collected from Energy Information Administration (EIA) (www.eia.gov).

\section{Insert Figure 1 here}

To perform a meaningful comparison between the performance of futures and other assets, the leverage in futures trading should be controlled in calculating futures returns. We follow the literature by assuming that the futures positions are fully 
collateralized (see, e.g., Hong and Yogo, 2012; de Roon et al., 2000; Gorton et al., 2013). Specifically, when an investor buys a contract with a futures price of 100 dollars, he/she should simultaneously invest 100 dollars in Treasury bills. The earning of this investor over a given period of time is the change in futures price and the interest on the 100 dollars. Suppose the futures prices at week $t$ a contract is $F_{t}$, the return in excess of risk-free rate (or net return) on a fully collateralized long position in futures contract is defined as,

$$
r_{t, o}=52 \times\left(\log \left(F_{t}\right)-\log \left(F_{t-1}\right)\right),
$$

The first order difference of log weekly price is multiplied by 52 to denote the annualized excess return. We use "WF1", "WF2", "WF3" and "WF4" to denote returns of crude oil futures Contract 1,2, 3 and 4, respectively.

Table 1 shows the descriptive statistics of excess returns of four futures contracts. We can see that the means of return are about 0.027 but the standardized deviations are much larger. The standardized deviations for the returns of futures with longer maturities are always lower. This is consistent with the Samuelson effect that volatility of futures price monotonically decreases as time-to-maturity increases (Samuelson, 1965). The Samuelson effect can be explained by the martingale property of future prices, together with the assumption that spot prices are generated by a mean-reverting process, which ensures that longer-term assets will exhibit less variance than shorter-term assets. Some other hypotheses are also explored to explain this maturity effect. For example, Bessembinder et al. (1996) point out that the key condition supporting Samuelson effect is the negative covariance between changes in 
sport prices and net carry costs (i.e., "negative covariance" hypothesis). Andersen and Danthine (1983) develop the "state variable" hypothesis to explain the time pattern of futures volatility. This hypothesis states that the resolution of uncertainty or information flow into underlying market is greater as delivery date closes.

We also examine some time series properties of return series. First, we test for the distribution property of returns. The Jarque and Bera statistics consistently reject the null hypothesis of normal distribution for all four return series at $1 \%$ level. The fat-tail distribution is also confirmed by the negative skewness and positive excess kurtosis for each return series. This finding motives us to use a Skew-t distribution to capture return dynamics. Second, we examine the unit root and find that all futures return series are stationary ${ }^{6}$. The stationarity enables us to model return volatility directly and not need to do any more transformations. Third, we analyze the serial auto-correlations using the Ljung and Box test. The statistics consistently show the significant auto-correlations. To take into account the property of serial correlation, we use AR(1) specification in modeling conditional mean of returns. Finally, we also perform ARCH test on the innovations generated from $\mathrm{AR}(1)$ for return series. The $F$-statistics suggest the existence of significant ARCH effect. This makes the GARCH-class models which can capture ARCH effect be much appreciated in modeling financial asset volatility.

\section{Insert Table 1 here}

\footnotetext{
${ }^{6}$ We test for the unit root using augmented ADF, PP and KPSS methods. To save space, we do not show the detailed description of these tests. The optimal lag lengths of ADF test are chosen based on Schwarz information criterion (SIC) and the optimal bandwidths of PP and KPSS are determined based on Newey-West criterion. The null hypothesis of ADF and PP tests is that the time series contains a unit root while that of KPSS test is stationarity. We assume only intercept in testing equations.
} 


\section{Empirical results}

In this section, we will first present the in-sample estimation results of GARCH-class models. Second, we analyze out-of-sample performances in density forecasting. Finally, we check the usefulness of volatility forecasts in futures investment.

\subsection{In-sample estimation results of GARCH-class models}

Tables A1-A4 in the appendix show the parameter estimation results of 9 GARCH-class models for returns of oil futures with different maturities. First, beginning with the standard $\operatorname{GARCH}(1,1)$, we can see that the persistence coefficient $\alpha+\beta$ is quite close to 1 for each futures contract, indicating a relatively high degree of volatility persistence. Second, turning to EGARCH, GJR and APARCH models which consider the asymmetric effect, we can find that the parameter $\gamma$ is significantly positive at $10 \%$ level. This result is consistent with the finding of "inverse leverage effect" 7 reported in the literature (see, e.g., Cheong, 2009; Mohammadi and Su, 2010). Third, looking at the estimation results of two GARCH models allowing for long memory (FIGARCH and HYGARCH), it is clear that the parameter $d$ is about 0.9 , thereby indicating strong long memory property. This result is consistent with the findings in the majority of the literature (see, e.g., Arouri et al., 2012; Tabak and Cajueiro, 2007; Wang and $\mathrm{Wu}, 2013)$. The two more complex models, FIEGARCH and FIAPARCH, confirm the existence of both long memory and asymmetric effect. We also give the results of diagnostic tests. The log likelihoods

\footnotetext{
7 This phenomenon is contrast with the "leverage effect" in the finance literature that stock market volatility is always higher when stock prices decrease than when stock price increase.
} 
$(\log \mathrm{L})$ suggest that FIEGARCH and FIAPARCH always fit the return data better than the other ones. Both LJB Q statistics and ARCH test statistics indicate that the ARCH effect in standardized innovations are not significant, implying that these GARCH-class models can well capture ARCH effect in oil future returns.

\subsection{Out-of-sample results in forecasting density}

We use the technique of rolling windows to do forecasting analysis. Specifically, we first divide the whole sample data into following two subsamples: (i) the in-sample data for parameter estimation contains the first 1000 observations from January 11, 1985 to March 5, 2004; and (ii) the out-of-sample data contains the last 587 observations for forecasting evaluation from March 12, 2004 to June 05, 2015. Then, the in-sample estimation window is rolled forward by adding a new observation and dropping the oldest observation. In this way, the sample size used in estimating parameters is fixed to be 1000 and the volatility forecasts do not overlap. The graphical illustration of volatility forecasts of WF1 generated by GARCH, GJR, FIGARCH and FIEGARCH are given in Figure $2^{8}$.

\section{Insert Figure 2 here}

We use the mean forecasts obtained from $\operatorname{AR}(1)$ and volatility forecasts from GARCH-class models to construct the density forecasts. The graphical illustration of predictive densities (log value) of WF1 returns is shown in Figure $3^{9}$. We can find that density forecasts from different GARCH-class models share the similar pattern. Some

\footnotetext{
${ }^{8}$ To save space, we do not plot the volatility forecasts of returns of other futures contracts but they are available upon request.

9 To save space, we do not plot the predictive densities for the other three contracts but they are available upon request.
} 
extreme forecasts occur during the period when exogenous events broke out. For example, the two lowest points can be related to the financial crisis in September 2008 and "Libya war" in February 2011, respectively.

\section{Insert Figure 3 here}

One question related to how to measure the accuracy of density forecasts is that the true distribution of return is unknown. This issue has been addressed in the literature by testing whether the predictive densities are correctly specified (see, e.g., Diebold et al., 1998; Bai, 2003). The measure based on the well-known Kullback-Leibler divergence or Kullback-Leibler Information Criterion (KLIC) can circumvent this problem without assuming the true distribution (Mitchell and Hall, 2005; Amisano and Giacomini, 2007). The KLIC chooses the model, which on average gives higher probability to events that actually occurred. As argued by Mitchell and Hall (2005), the KLIC provides a unified framework for evaluating, comparing and combining density forecasts. It measures the distance between the true and predicted densities and can be calculated using the following equation:

$$
\mathrm{KLIC}_{i}=E\left[\ln f\left(y_{t}\right)-\ln f_{i}\left(y_{t}\right)\right],
$$

where $E$ denotes the expectation operator. The symbols $f$ and $f_{i}$ are the true and predicted densities of model $i$, respectively, where $i=1,2, \ldots N$ and $N$ is the total number of the models $\left(f\left(y_{t}\right)>0, f_{i}\left(y_{t}\right)>0\right)$. The symbol $y_{t}$ is the realization of excess return of oil futures. The KLIC is a sensible measure of accuracy since it chooses the model which on average gives higher probability to events that have actually occurred. Therefore, the greater KLIC implies a lower accuracy of density 
forecasts of model $i$. To compare the KLIC of predictive densities of different models $\left(f_{i}\right)$, we only need to evaluate the last term of the expectation in Equation (13), which is the expected logarithmic score $(\ln S)$ :

$$
E\left[\ln S_{i}\right]=E\left[\ln f_{i}\left(y_{t}\right)\right],
$$

It is easy to derive that $E \ln S_{i}>E \ln S_{j}$ implies $K L I C_{i}<K L I C_{j}$. Under some regularity conditions, a consistent estimate of $E \ln S_{i}$ can be obtained from the average of the sample logarithmic scores:

$$
\ln S_{i}=\frac{1}{T} \sum_{t=1}^{T} \ln f_{i, t}\left(y_{t}\right)
$$

where $T$ is the total number of out-of-sample observations. Therefore, we actually do not need to know the true density to compare the accuracy of different predicted densities. To statistically determine whether the accuracy of the density forecasts of two different models are significant different, we employ the test given in Mitchell and Hall (2005).

Table 2 shows the average logarithmic scores $(\ln S)$ of density forecasts. We can observe some consistent patterns by observing forecasting performances of different GARCH-class models. First, GARCH with asymmetric effects (EGARCH, GJR and APARCH) always result in more accurate density forecasts than the simple $\operatorname{GARCH}(1,1)$. This evidence suggests the importance of allowing for asymmetry in modeling and forecasting volatility. Second, the long memory GARCH models (e.g., FIGARCH, FIEGARCH and FIAPARCH) perform better than their short memory counterparts (e.g., GARCH, EGARCH and APARCH). This finding indicates that considering long memory in volatility can improve the density forecast accuracy. 
Third, we can find that for the first three futures contracts, WF1, WF2 and WF3, the density forecasts of FIEGARCH are more accurate than the other GARCH-class models. The statistics of Mitchell and Hall (2005) test indicate that differences of density forecast accuracy between FIEGARCH and each of its competitors are significant for these three contracts. For the futures contracts of WF4, the average logarithmic scores of FIEGARCH forecasts are slightly less accurate than FIAPARCH, but the difference of their forecasting accuracy is not statistically significant. Therefore, we can generally conclude that FIEGARCH display superior performance in forecasting return density of crude oil.

\section{Insert Table 2 here}

It has been documented that the performances of volatility models depend on the choice of evaluation criteria. Due to this consideration, we use an alternative criterion, failure rate (FR), which measures how often Model $i$ fails to generate better predictive densities than Model $j$ (the benchmark model). This criterion is given by,

$$
F R_{i j}=\frac{1}{T} \sum_{t=1}^{T} l_{i j, t}, l_{i j, t}=I\left(f_{i, t}\left(y_{t}\right)<f_{j, t}\left(y_{t}\right)\right)
$$

where $I($.$) is an indicator function which takes the value of 1$ when the condition in the parenthesis is satisfied and takes the value of 0 otherwise. Obviously, FR quantifies the probability that Model $i$ generates less accurate density forecast than Model $j$. Therefore, a $F R_{i j}$ higher than 0.5 implies that Model $i$ is likely to result in less accurate forecast than Model $j$. Compared with the criterion of $\ln S$, FR is less affected by outliers.

Table 3 gives the ratio that each of the GARCH-class models fail to beat 
FIEGARCH in density forecasting, namely failure ratio (FR). We can see that FR is greater than 0.5 for most of the competitors of FIEGARCH. This result suggests that FIEGARCH forecasts are more accurate most of time. Moreover, the t-statistics clearly indicate that these FRs are significantly different from 0.5 . That is, it is significantly more frequent that FIEGARCH predicts oil return density better than its competitors.

\section{Insert Table 3 here}

In order to further understand the relative forecasting performances of GARCH-class models, it is interesting to find if the time series of indicator function $l_{i j, t}$ in Eq.(16) exhibit persistence of some kind or are independently distributed. This is important, because if the values of $l_{i j, t}$ are independently distributed, it would be impossible to predict whether FIEGARCH is better than the others. To address this issue, we follow Sarno and Valente (2009) by using a fairly general test for the null hypothesis that $l_{i j, t}$ series are independent and identically distributed against an unspecified form of dependence, namely Broock et al.(1996) test. The results reported in Table 4 show that for almost all futures returns examined, the null hypothesis is rejected regardless of which competitor is considered. This result indicates that the event that FIEGARCH displays superior forecasting performance persistently.

\section{Insert Table 4 here}

\subsection{Portfolio exercise}

We have analyzed the forecasting performances of GARCH-class models in the statistical sense. Actually, futures investors are more concerned about the economic 
value of density forecasts. Specifically, they are more interested in how well these density forecasts perform in portfolio exercise. In order to examine the economic significance of density forecasts, we consider a mean-variance investor who invests in a portfolio that contains two assets, oil futures and risk-free Treasury bill. Accordingly, the utility of investing in this portfolio is given as follow:

$$
U_{t}=E\left(w_{t} r_{t, o}+r_{t, f}\right)-\frac{1}{2} \gamma \operatorname{var}\left(w_{t} r_{t, o}+r_{t, f}\right),
$$

where $w_{t}$ is the weight of crude oil futures in the portfolio, $r_{t, o}$ is the excess return of oil futures, $r_{t, f}$ is the risk-free bill rate and $\gamma$ is the risk aversion coefficient. In following analysis, we will use $\gamma=3$ and then verify whether the portfolio performances are robust to alternative risk aversion coefficients.

According to Equation (17), we can easily derive that at the end of month $t$, the investor determines the optimal weight of oil futures at month $t+1$ as:

$$
w_{t+1}^{*}=\frac{1}{\gamma}\left(\frac{\hat{r}_{t+1, o}}{\hat{\sigma}_{t+1}^{2}}\right) \text {, }
$$

where $\hat{r}_{t+1, o}$ and $\hat{\sigma}_{t+1}^{2}$ are the mean and volatility forecasts of oil excess returns, respectively.

In this way, the portfolio return at month $t+1$ is given by:

$$
R_{t+1, p}=w_{t}^{*} r_{t+1, o}+r_{t+1, f}-\tau\left|w_{t+1}^{*}-w_{t}\right|,
$$

where the transaction costs are $\tau$ percentage points of the value traded. Note that the transaction costs in futures markets range from $0.0004 \%$ (low cost) to $0.033 \%$ (high cost) (Locke and Venkatesh, 1997), which is much lower than the conservative 0.5\% estimate of Jegadeesh and Titman (1993). In this paper, we report the results corresponding to the high cost of $0.033 \%$. We also use the low cost of $0.0004 \%$ and 
obtain the similar results qualitatively. To save space, they are not reported in current version but are available upon request.

We employ two popular criteria to evaluate the performance of portfolios constructed based on density forecasts. The first is the Sharpe ratio:

$$
S R=\frac{\bar{\mu}_{p}}{\bar{\sigma}_{p}}
$$

where $\bar{\mu}_{p}$ and $\bar{\sigma}_{p}$ are the mean and standard deviation of portfolio excess returns, respectively. For comparison, we follow Marquering and Verbeek (2004) in considering a simple benchmark strategy of holding $50 \%$ of the wealth in the risky asset (crude oil futures) and 50\% in the risk-free asset. This strategy is also called as "passive strategy" or "static strategy". We calculate the difference of Sharpe ratios between the portfolio formed by forecasts of each GARCH-class model and this benchmark portfolio to find how well the forecasting performances of GARCH-class models are. We multiply this difference by the square root of 12 to denote the annualized value.

The Sharpe ratio is argued to overestimate the risk in case of time-varying volatility. To overcome this drawback of Sharpe ratio, we go back to the mean-variance investor and use following utility measure of certainty equivalent return (CER) to evaluate portfolio performance:

$$
\mathrm{CER}_{p}=\hat{\mu}_{p}-\frac{\gamma}{2} \hat{\sigma}_{p}^{2}
$$

where $\hat{\mu}_{p}$ and $\hat{\sigma}_{p}^{2}$ are the mean and variance of portfolio returns over the out-of-sample period, respectively. To be precise, this definition refers to the expected utility of a mean-variance investor. It can be shown that this is also approximately the 
CER of an investor with quadratic utility ${ }^{10}$ (DeMiguel et al., 2009). We calculate the difference of CERs between the portfolio formed by forecasts of each GARCH-class model and the benchmark portfolio constructed by passive strategy. Intuitively, this difference denotes the maximum fee, an investor with a given level of risk aversion, would be willing to pay to switch from the benchmark strategy to the dynamic strategy under consideration. We multiply this difference by 100 to interpret the percentage performance fee.

Table 5 reports the performances of portfolios constructed on the density forecasts of oil futures returns. We first use the risk aversion coefficient $\gamma=3$ (Panel A). All GARCH-class models lead to positive gains of Sharpe ratios over the benchmark of passive strategy. This result implies that the GARCH-class strategy performs better than the benchmark of static strategy. We use the method suggested by Jobson and Korkie (1981) after making the correction pointed out in Memmel (2003) to test whether the Sharpe ratios of each GARCH strategy and the benchmark strategy are statistically distinguishable. Our evidence strongly rejects the null hypothesis of equal Sharpe ratios, indicating that the benchmark strategy is significantly outperformed by GARCH. Additionally, we can also find that the Sharpe ratios of portfolios formed by different GARCH-class models are quite close, which ranges from 1 to 1.1, depending on the model specification and the maturity of futures contracts. The forecasting results evaluated by gains of CER over benchmark strategy further confirm our finding based on Sharpe ratios. The values of market timing for

\footnotetext{
${ }^{10}$ Following the common practice, we still interpret it as the CER for a strategy.
} 
different dynamic strategies based on GARCH-class models, relative to the static strategy, are about $18 \%$ to $20 \%$ p.a.. The gains of utility are higher than stock portfolio reported in the literature (see, e.g., Rapach et al., 2010).

\section{Insert Table 5 here}

\subsection{Robustness analysis}

We have found the usefulness of GARCH-class models in asset allocation. In this subsection, we show the robustness of our main finding in following two ways. First, we adjust the degree of risk aversion from $\gamma=3$ to $\gamma=6$. According to Equation (18), a higher value of $\gamma$ implies that the risky asset (i.e., crude oil futures) receives lower weights in an optimal portfolio for an investor with mean-variance utility. Panel B of Table 5 reports the performances of portfolios for a higher degree of risk aversion $(\gamma=6)$. The relative Sharpe ratios become slightly higher and the gains of utility become lower with the change of risk aversion degree from $\gamma=3$ to $\gamma=6$. More importantly, we can still find that the benchmark of static strategy is significantly outperformed by the dynamic strategy based on each of 9 GARCH-class models under consideration. This result confirms the usefulness of GARCH in oil futures investment. Different GARCH-class models display close performances in portfolio management.

Second, we examine the impacts of portfolio rebalancing frequency on the performances of GARCH-based trading strategies. We have used weekly data and assume that the portfolio is rebalanced every week. Do the results change when 
rebalancing frequency is restricted, i.e., from weekly to monthly? ${ }^{11}$ To answer this question, we redo empirical analysis using monthly futures data. We consider two different degrees of risk aversion and show the portfolio performances in Table 6 . We can find that comparing with the results for weekly rebalancing frequency, the portfolio performances become a bit worse when the portfolio is rebalanced monthly. However, the gains of Sharpe ratios of GARCH-based strategies over the benchmark of static strategy at $10 \%$ level are significantly positive. This result also holds under the evaluation criterion of CER. The usefulness of GARCH models for oil futures investors is confirmed with the change of portfolio rebalancing frequency.

\section{Insert Table 6 here}

\section{Concluding remarks and some discussions}

The forecasts of return density are of great importance for portfolio management. In this paper, we evaluate the performances of several popular GARCH-class models in forecasting futures return density of crude oil. First, we use a measure of expected logarithmic score $(\ln S)$ and find that FIEGARCH which accommodates both long memory and asymmetry performs significantly better than the other GARCH-class models under consideration. FIEGARCH also generates less accurate density forecasts significantly less frequently than its competitors according to a failure rate (FR) criterion.

Second, in order to assess the economic value of density forecasts, we consider an investor with mean-variance preference who allocates his or her wealth between

\footnotetext{
${ }^{11}$ We thank an anonymous referee for this helpful suggestion.
} 
crude oil futures and risk-free bill. The weight of oil futures in the portfolio is determined by density forecasts. We use Sharpe ratio and certainty equivalent return (CER) to evaluate the portfolio performance. For comparison, a simple static strategy of holding $50 \%$ of the wealth in the risky asset (crude oil futures) and $50 \%$ in the risk-free asset is taken as the benchmark. We find that GARCH-based dynamic strategies perform significantly better than the benchmark strategy. The superior performances of GARCH-based strategies are further demonstrated to be robust for the change of degree of risk aversion and the restriction of portfolio rebalancing frequency. The portfolios formed by different GARCH-based strategies are close.

Our findings have important implications. For example, it has been generally accepted that both high oil price and uncertainty have important impacts on macroeconomic activity. In this sense, accurate density forecasts of oil returns are helpful for improving the policy effectiveness. For policy makers, GARCH models are useful to do policy decision. GARCH-implied trading strategies perform better than passive strategy. Therefore, dynamic strategies rather than static strategies should be more appreciated by oil market investors. Our oil portfolio performances are better than stock portfolios reported in the literature. For international investors, oil futures is a better investing instrument than stocks.

\section{Acknowledgements}

This work is supported by the National Science Foundation of China under the grant numbers 71501095 (Yudong Wang), 71401077 (Li Liu) and 71320107002 (Chongfeng Wu). 


\section{References}

Aloui, C., Mabrouk, S., 2010. Value-at-risk estimations of energy commodities via long-memory, asymmetry and fat-tailed GARCH models. Energy Policy 38, 2326-2339.

Amisano, G., Giacomini, R., 2007. Comparing density forecasts via weighted likelihood ratio tests. Journal of Business \& Economic Statistics 25, 177-190.

Anderson, R.W., Danthine, J., 1983. The time pattern of hedging and the volatility of futures prices. Review of Economic Studies 50, 249-266.

Agnolucci, P., 2009. Volatility in crude oil futures: a comparison of the predictive ability of GARCH and implied volatility models. Energy Economics 31, $316-321$.

Arouri, M. E. H., Lahiani, A., Lévy, A., Nguyen, D. K., 2012. Forecasting the conditional volatility of oil spot and futures prices with structural breaks and long memory models. Energy Economics 34, 283-293.

Bai, J., 2003. Testing parametric conditional distributions of dynamic models. Review of Economics and Statistics 85, 531-549.

Baillie, R. T., Bollerslev, T., Mikkelsen, H. O., 1996. Fractionally integrated generalized autoregressive conditional heteroskedasticity. Journal of econometrics 74, 3-30.

Bandi, F. M., Russell, J. R., 2008. Microstructure noise, realized variance, and optimal sampling. The Review of Economic Studies 75, 339-369.

Baumeister, C., Peersman, G., 2013. Time-varying effects of oil supply shocks on the Economy. American Economic Journal: Macroeconomics 5, 1-28.

Bessembinder, H., Coughenour, J.F., Seguin, P.J., Smoller, M.M., 1996. Is there a 
term structure of futures volatilities? Re-evaluating the Samuelson hypothesis. Journal of Derivatives 4, 45-58.

Bollerslev, T., 1986. Generalized autoregressive conditional heteroskedasticity. Journal of Econometrics 31, 307-327.

Bollerslev, T., Engle, R.F., Nelson, D., 1994. ARCH models. In: Engle, R.F., McFadden, D.L. (Eds.), Handbook of Econometrics, vol. IV. Elsevier Science BV, Amsterdam, pp. 2961-3038.

Broock, W. A., Scheinkman, J. A., Dechert, W. D., \& LeBaron, B. (1996). A test for independence based on the correlation dimension. Econometric reviews, 15(3), 197-235.

Chang, K. L., 2012. Volatility regimes, asymmetric basis effects and forecasting performance: An empirical investigation of the WTI crude oil futures market. Energy Economics 34, 294-306.

Cheng, I. H., Xiong, W., 2013. The financialization of commodity markets. National Bureau of Economic Research. No. w19642.

Cheong, C. W., 2009. Modeling and forecasting crude oil markets using ARCH-type models. Energy policy 37, 2346-2355.

Chkili, W., Hammoudeh, S., Nguyen, D. K., 2014. Volatility forecasting and risk management for commodity markets in the presence of asymmetry and long memory. Energy Economics 41, 1-18.

Cont, R., 2001. Empirical properties of asset returns: stylized facts and statistical issues. Quantitative Finance 1, 223-236.

Davidson, J., 2004. Moment and memory properties of linear conditional heteroscedasticity models, and a new model. Journal of Business \& Economic 
Statistics 22, 16-29.

DeMiguel, V., Garlappi, L., Uppal, R., 2009. Optimal versus naive diversification: How inefficient is the 1/N portfolio strategy?. Review of Financial Studies 22, 1915-1953.

De Roon, F. A., Nijman, T. E., Veld, C., 2000. Hedging pressure effects in futures markets. Journal of Finance, 1437-1456.

Diebold, F. X., Gunther, T., Tay, A. S., 1998. Evaluating density forecasts with applications to finance and management. International Economic Review 39, 863-883.

Ding, Z., Granger, C.W.J., Engle, R.F., 1993. A long memory property of stock market returns and a new model. Journal of Empirical Finance 1, 83-106.

Engle, R.F., 1982. Autoregressive conditional heteroskedasticity with estimates of the variance of United Kingdom inflation. Econometrica 50, 987-1007.

Engle, R.F., Bollerslev, T., 1986. Modelling the persistence of conditional variances. Econometric Reviews 5, 1-50.

Fan, Y., Zhang, Y.J., Tsaic, H.T., Wei, Y.M., 2008. Estimating 'value at risk' of crude oil price and its spillover effect using the GED-GARCH approach. Energy Economics 30, 3156-3171.

Ferreira, M. A., Santa-Clara, P., 2011. Forecasting stock market returns: The sum of the parts is more than the whole. Journal of Financial Economics 100, 514-537.

Giot, P., Laurent, S., 2003. Market risk in commodity markets: a VaR approach. Energy Economics 25, 435-457.

Glosten, L.R., Jagannathan, R., Runkle, D.E., 1993. On the relation between the expected value and the volatility of the nominal excess return on stocks. Journal 
of Finance 48, 1779-1801.

Gorton, G. B., Hayashi, F., Rouwenhorst, K. G., 2013. The fundamentals of commodity futures returns. Review of Finance 17, 35-105.

Hansen, B. E., 1994. Autoregressive conditional density estimation. International Economic Review 35, 705-730.

Hansen, P. R., Lunde, A., 2005. A forecast comparison of volatility models: does anything beat a GARCH $(1,1)$ ?. Journal of applied econometrics 20, 873-889.

Haugom, E., Langeland, H., Molnár, P., Westgaard, S., 2014. Forecasting Volatility of the US Oil Market. Journal of Banking \& Finance 47, 1-14.

Høg, E., Tsiaras, L., 2011. Density forecasts of crude-oil prices using option-implied and ARCH-type models. Journal of Futures Markets 31, 727-754.

Hong, H., Yogo, M., 2012. What does futures market interest tell us about the macroeconomy and asset prices?. Journal of Financial Economics 105, 473-490.

Hou, A., Suardi, S., 2012. A nonparametric GARCH model of crude oil price return volatility. Energy Economics 34, 618-626.

Ielpo, F., Sevi, B., 2013. Forecasting the density of oil futures returns using model-free implied volatility and high-frequency data. Working paper.

Jegadeesh, N., Titman, S., 1993. Returns to buying winners and selling losers: Implications for stock market efficiency. Journal of Finance 48, 65-91.

Jobson, J. D., Korkie, B. M., 1981. Performance hypothesis testing with the Sharpe and Treynor measures. The Journal of Finance 36, 889-908.

Jones, C., Kaul, G., 1996. Oil and stock markets. Journal of Finance 51, 463-491.

Kang, S.H., Kang, S.M., Yoon, S.M., 2009. Forecasting volatility of crude oil markets. Energy Economics 31, 119-125. 
Kang, S. H., Yoon, S. M., 2013. Modeling and forecasting the volatility of petroleum futures prices. Energy Economics 36, 354-362.

Kilian, L., 2009. Not all oil price shocks are alike: disentangling demand and supply shocks in the crude oil market. American Economic Review 99, 1053-1069.

Kilian, L., Park, C., 2009. The impact of oil price shocks on the U.S. stock market. International Economic Review 50, 1267-1287.

Liu, L., Wan, J., 2012. A study of Shanghai fuel oil futures price volatility based on high frequency data: Long-range dependence, modeling and forecasting. Economic Modelling, 29, 2245-2253.

Locke, P., Venkatesh, P., 1997. Futures market transaction costs. Journal of Futures Markets 17, 229--245.

Lombardi, M. J., Ravazzolo, F., 2012. Oil price density forecasts: exploring the linkages with stock markets. Working paper.

Memmel, C., 2003. Performance Hypothesis Testing with the Sharpe Ratio. Finance Letters 1, 21-23.

Mohammadi, H., Su, L. 2010. International evidence on crude oil price dynamics: applications of ARIMA-GARCH models. Energy Economics 32, 1001-1008.

Mork, K.A., 1989. Oil and the macroeconomy when prices go up and down: An extension of Hamilton's results. Journal of Political Economy 91, 740-744.

Mahringer, S., Prokopczuk, M., 2015. An Empirical Model Comparison for Valuing Crack Spread Options. Energy Economics 51, 177-187.

Marquering, W., Verbeek, M., 2004. The Economic Value of Predicting Stock Index Returns and Volatility. Journal of Financial and Quantitative Analysis 39, 407-429. 
Mitchell, J., Hall, S. G., 2005. Evaluating, Comparing and Combining Density Forecasts Using the KLIC with an Application to the Bank of England and NIESR 'Fan' Charts of Inflation. Oxford bulletin of economics and statistics 67, 995-1033.

Narayan, P.K., Narayan, S., 2007.Modelling oil price volatility. Energy Policy 35, 6549-6553.

Nelson, D. B., 1991. Conditional heteroskedasticity in asset returns: A new approach. Econometrica: Journal of the Econometric Society 59, 347-370.

Nomikos, N.K., Pouliasis, P.K., 2011. Forecasting petroleum futures markets volatility: The role of regimes and market conditions. Energy Economics 33, 321-337.

Patton, A. J., 2011. Volatility forecast comparison using imperfect volatility proxies. Journal of Econometrics 160, 246-256.

Rapach, D. E., Strauss, J. K., Zhou, G., 2010. Out-of-sample equity premium prediction: Combination forecasts and links to the real economy. The Review of Financial Studies 23, 821-862.

Sadorsky, P., 1999. Oil price shocks and stock market activity. Energy Economics 21, 449-469.

Sadorsky, P., 2006. Modeling and forecasting petroleum futures volatility. Energy Economics 28, 467-488.

Samuelson, P., 1965. Proof that properly anticipated prices fluctuate randomly. Industrial Management Review 6, 41-69.

Sarno, L., Valente, G., 2009. Exchange rates and fundamentals: Footloose or evolving relationship?. Journal of the European Economic Association 7, 786-830. 
Sévi, B., 2014. Forecasting the volatility of crude oil futures using intraday data. European Journal of Operational Research 235, 643-659.

Tabak, B.M., Cajueiro, D.O., 2007. Are the crude oil markets becoming weakly efficient over time? A test for time-varying long-range dependence in prices and volatility. Energy Economics 29, 28-36.

Tang, K., Xiong, W., 2012. Index investment and the financialization of commodities. Financial Analysts Journal 68, 54-74.

Wang, Y., Wu, C., 2012. Forecasting energy market volatility using GARCH models: Can multivariate models beat univariate models? Energy Economics 34, 2167-2181.

Wang, Y., Wu, C., 2013. Efficiency of Crude Oil Futures Markets: New Evidence from Multifractal Detrending Moving Average Analysis. Computational Economics 42, 393-414.

Wang, Y., Wu, C., Yang, L., 2013. Oil price shocks and stock market activities: Evidence from oil-importing and oil-exporting countries. Journal of Comparative Economics 41, 1220-1239.

Wang, Y., Wu, C., Yang, L., 2015. Hedging with Futures: Does Anything Beat the Naïve Hedging Strategy?. Management Science. Forthcoming.

Wei, Y., Wang, Y., Huang, D., 2010. Forecasting crude oil market volatility: Further evidence using GARCH-class models. Energy Economics 32, 1447-1484.

Youssef, M., Belkacem, L., Mokni, K., 2015. Value-at-Risk estimation of energy commodities: A long memory GARCH-EVT approach. Energy Economics 51, $99-110$. 


\section{Appendix}

Table A1 Estimation results of GARCH-class models for WF1 returns

\begin{tabular}{|c|c|c|c|c|c|c|c|c|c|}
\hline & GARCH & EGARCH & GJR & APARCH & IGARCH & FIGARCH & HYGARCH & FIEGARCH & FIAPARCH \\
\hline \multicolumn{10}{|c|}{ Mean equation } \\
\hline \multirow[t]{2}{*}{$\mu$} & 0.044 & 0.001 & 0.002 & 0.001 & 0.044 & 0.043 & 0.040 & 0.023 & -0.011 \\
\hline & $(0.824)$ & $(0.010)$ & $(0.032)$ & $(0.027)$ & $(0.816)$ & $(0.760)$ & $(0.723)$ & $(0.005)$ & $(-0.260)$ \\
\hline \multirow[t]{2}{*}{$\lambda$} & $0.154^{* * * *}$ & $0.157 * * *$ & $0.158^{* * * *}$ & $0.156^{* * *}$ & $0.155^{* * * *}$ & $0.154 * * *$ & $0.154^{* * *}$ & $0.161 * * *$ & $0.159^{* * * *}$ \\
\hline & (5.698) & $(5.865)$ & (5.709) & (5.697) & $(5.922)$ & (5.924) & $(5.811)$ & (6.657) & (7.758) \\
\hline \multicolumn{10}{|c|}{ Volatility equation } \\
\hline \multirow[t]{2}{*}{$\omega$} & $0.129 * * *$ & $1.498 * * *$ & $0.124 * * *$ & $0.078^{* *}$ & $0.073^{* * * *}$ & $0.084 * * *$ & $0.143^{* * *}$ & 0.569 & $0.076^{* * * *}$ \\
\hline & $(3.075)$ & $(8.271)$ & (2.969) & $(2.450)$ & (3.279) & (3.117) & $(3.125)$ & $(-0.926)$ & (4.937) \\
\hline \multirow[t]{2}{*}{$\alpha$} & $0.105^{* * * *}$ & 0.204 & $0.063 * * *$ & $0.101 * * *$ & $0.126^{* * * *}$ & & & & \\
\hline & $(5.950)$ & $(0.292)$ & $(3.240)$ & (6.496) & (7.115) & & & & \\
\hline \multirow{2}{*}{$\beta$} & $0.867 * * *$ & $0.965^{* * *}$ & $0.873^{* * *}$ & $0.887 * * *$ & 0.874 & $0.823 * * *$ & $0.845^{* * *}$ & $0.948 * * *$ & $0.830^{* * *}$ \\
\hline & $(47.94)$ & $(110.0)$ & (51.99) & $(50.23)$ & & $(26.52)$ & (11.79) & (66.28) & $(27.46)$ \\
\hline \multirow[t]{2}{*}{$\gamma$} & & $0.155^{*}$ & $0.072^{*}$ & $0.332 *$ & & & & $0.114^{*}$ & $0.375^{* * *}$ \\
\hline & & (1.795) & (1.941) & (1.791) & & & & (1.818) & $(2.896)$ \\
\hline \multirow[t]{2}{*}{$\delta$} & & & & $1.240^{* * *}$ & & & & & $0.830^{* * * *}$ \\
\hline & & & & (3.166) & & & & & (3.102) \\
\hline \multirow[t]{2}{*}{$\varphi$} & & & & & & 0.065 & -0.002 & 0.453 & 0.023 \\
\hline & & & & & & $(0.653)$ & $(-0.025)$ & $(0.577)$ & $(0.346)$ \\
\hline \multirow[t]{2}{*}{$d$} & & & & & & $0.859 * * *$ & $0.956^{* * *}$ & $0.168^{* * *}$ & $0.873^{* * * *}$ \\
\hline & & & & & & $(8.120)$ & $(42.29)$ & $(2.001)$ & (10.65) \\
\hline \multirow[t]{2}{*}{$\log k$} & & & & & & & $-0.031^{*}$ & & \\
\hline & & & & & & & $(-1.926)$ & & \\
\hline \multicolumn{10}{|c|}{ Diagnostic test } \\
\hline $\log (\mathrm{L})$ & -3246.6 & -3235.8 & -3241.4 & -3237.8 & -3250.4 & -3249.0 & -3246.1 & -3233.9 & -3236.9 \\
\hline \multirow[t]{2}{*}{$Q^{2} 10$} & 4.319 & 4.619 & 3.479 & 3.506 & 4.589 & 4.398 & 4.181 & 7.037 & 5.099 \\
\hline & {$[0.827]$} & {$[0.797]$} & {$[0.901]$} & {$[0.899]$} & {$[0.800]$} & {$[0.820]$} & {$[0.840]$} & {$[0.503]$} & {$[0.747]$} \\
\hline \multirow[t]{2}{*}{$\mathrm{ARCH}(10)$} & 0.414 & 0.448 & 0.344 & 0.337 & 0.448 & 0.419 & 0.401 & 0.712 & 0.493 \\
\hline & {$[0.941]$} & [0.923] & [0.969] & {$[0.971]$} & {$[0.923]$} & {$[0.938]$} & [0.947] & {$[0.714]$} & [0.895] \\
\hline
\end{tabular}

Notes: the numbers in parentheses are t-statistics of the estimates. $\log (\mathrm{L})$ is the logarithm maximum likelihood function value. $Q^{2} 10$ is the Ljung-Box(1978) Q-statistics of order 10 on the squared standardized residuals. $\mathrm{ARCH}(10)$ is the nonheteroscedasticity statistics of order 10. P-values of the statistics are reported in square brackets. *,** and *** denote significance at the $10 \%, 5 \%$ and $1 \%$ levels, respectively. 
Table A2 Estimation results of GARCH-class models for WF2 returns

\begin{tabular}{|c|c|c|c|c|c|c|c|c|c|}
\hline & GARCH & EGARCH & GJR & APARCH & IGARCH & FIGARCH & HYGARCH & FIEGARCH & FIAPARCH \\
\hline \multicolumn{10}{|c|}{ Mean equation } \\
\hline \multirow[t]{2}{*}{$\mu$} & 0.037 & -0.012 & 0.002 & -0.025 & 0.033 & 0.027 & 0.029 & -0.003 & -0.010 \\
\hline & $(0.716)$ & $(-0.244)$ & $(0.034)$ & $(-0.623)$ & $(0.622)$ & $(0.507)$ & $(0.552)$ & $(-0.065)$ & $(-0.210)$ \\
\hline \multirow[t]{2}{*}{$\lambda$} & $0.172 * * *$ & $0.166^{* * *}$ & $0.175^{* * *}$ & $0.154 * * *$ & $0.172 * * *$ & $0.174 * * *$ & $0.174 * * *$ & $0.165^{* * *}$ & $0.151^{* * * *}$ \\
\hline & (6.373) & $(6.322)$ & $(6.341)$ & $(4.214)$ & $(6.621)$ & $(6.858)$ & $(6.672)$ & $(6.262)$ & (7.011) \\
\hline \multicolumn{10}{|c|}{ Volatility equation } \\
\hline \multirow[t]{2}{*}{$\omega$} & $0.104 * * *$ & $1.312^{* * *}$ & $0.103^{* * *}$ & $0.045^{* * * *}$ & $0.051^{* * * *}$ & $0.066^{* * *}$ & $0.128^{* * *}$ & $1.402^{* * *}$ & $0.063^{* * * *}$ \\
\hline & $(3.180)$ & $(6.893)$ & $(3.000)$ & (3.344) & $(3.339)$ & $(2.819)$ & (3.095) & $(5.052)$ & $(5.059)$ \\
\hline \multirow[t]{2}{*}{$\alpha$} & $0.088^{* * *}$ & 0.441 & $0.050^{* * *}$ & $0.078 * * *$ & $0.107^{* * *}$ & & & & \\
\hline & (5.906) & $(0.461)$ & $(3.040)$ & $(5.112)$ & $(6.178)$ & & & & \\
\hline \multirow{2}{*}{$\beta$} & $0.884 * * *$ & $0.970 * * *$ & $0.887 * * *$ & $0.911^{* * *}$ & 0.893 & $0.814^{* * * *}$ & $0.839 * * *$ & $0.943^{* * *}$ & $0.827^{* * *} *$ \\
\hline & $(51.97)$ & (123.9) & (51.89) & $(68.31)$ & & (22.79) & (42.43) & $(65.29)$ & (53.18) \\
\hline \multirow[t]{2}{*}{$\gamma$} & & 0.113 & $0.067 * *$ & $0.539 * * *$ & & & & 0.085 & $0.517 * * *$ \\
\hline & & $(1.562)$ & $(2.013)$ & $(2.735)$ & & & & $(1.068)$ & $(3.335)$ \\
\hline \multirow[t]{2}{*}{$\delta$} & & & & $0.617^{*}$ & & & & & 0.588 \\
\hline & & & & $(1.661)$ & & & & & \\
\hline \multirow[t]{2}{*}{$\varphi$} & & & & & & 0.079 & 0.010 & 0.398 & 0.142 \\
\hline & & & & & & $(0.803)$ & $(0.130)$ & $(0.312)$ & $(0.161)$ \\
\hline \multirow[t]{2}{*}{$d$} & & & & & & $0.794 * * *$ & $0.905 * * *$ & $0.230^{* *}$ & $0.750^{* * * *}$ \\
\hline & & & & & & (7.190) & (11.30) & $(2.337)$ & (6.556) \\
\hline \multirow[t]{2}{*}{$\log k$} & & & & & & & $-0.035^{* *}$ & & \\
\hline & & & & & & & $(-2.032)$ & & \\
\hline \multicolumn{10}{|c|}{ Diagnostic test } \\
\hline $\log (\mathrm{L})$ & -3118.2 & -3101.8 & -3112.8 & -3102.5 & -3123.0 & -3119.4 & -3116.3 & -3099.5 & -3099.5 \\
\hline \multirow[t]{2}{*}{$Q^{2}(10)$} & 2.722 & 2.450 & 2.813 & 2.666 & 3.338 & 2.257 & 2.105 & 1.941 & 2.385 \\
\hline & {$[0.951]$} & [0.964] & {$[0.946]$} & [0.954] & {$[0.911]$} & {$[0.972]$} & {$[0.978]$} & {$[0.983]$} & [0.967] \\
\hline \multirow[t]{2}{*}{$\mathrm{ARCH}(10)$} & 0.272 & 0.237 & 0.293 & 0.266 & 0.342 & 0.217 & 0.203 & 0.184 & 0.224 \\
\hline & [0.987] & {$[0.993]$} & {$[0.983]$} & {$[0.988]$} & {$[0.970]$} & {$[0.995]$} & [0.996] & {$[0.997]$} & [0.994] \\
\hline
\end{tabular}

Notes: See Table A1. 
Table A3 Estimation results of GARCH-class models for WF3 returns

\begin{tabular}{|c|c|c|c|c|c|c|c|c|c|}
\hline & GARCH & EGARCH & GJR & APARCH & IGARCH & FIGARCH & HYGARCH & FIEGARCH & FIAPARCH \\
\hline \multicolumn{10}{|c|}{ Mean equation } \\
\hline \multirow[t]{2}{*}{$\mu$} & 0.037 & -0.011 & 0.006 & -0.031 & 0.032 & 0.026 & 0.029 & -0.003 & -0.044 \\
\hline & $(0.773)$ & $(-0.227)$ & $(0.121)$ & $(-0.681)$ & $(0.670)$ & $(0.540)$ & $(0.603)$ & $(-0.056)$ & $(-0.670)$ \\
\hline \multirow[t]{2}{*}{$\lambda$} & $0.173^{* * *}$ & $0.176^{* * *}$ & $0.177 * * *$ & $0.159^{* * *}$ & $0.173^{* * *}$ & $0.176^{* * *}$ & $0.176 * * *$ & $0.175^{* * *}$ & $0.138 * * *$ \\
\hline & $(6.478)$ & $(6.668)$ & (6.498) & (248.9) & (6.773) & (7.008) & (6.789) & $(6.640)$ & $(4.121)$ \\
\hline \multicolumn{10}{|c|}{ Volatility equation } \\
\hline \multirow[t]{2}{*}{$\omega$} & $0.089^{* * *}$ & $1.185^{* * *}$ & $0.090 * * *$ & $0.041^{* * * *}$ & $0.045^{* * *}$ & $0.059 * * *$ & $0.111^{* * *}$ & $1.274 * * *$ & $0.055^{* * *}$ \\
\hline & $(3.122)$ & $(6.027)$ & (2.959) & $(3.725)$ & $(3.263)$ & (2.786) & (3.054) & $(4.621)$ & $(4.001)$ \\
\hline \multirow[t]{2}{*}{$\alpha$} & $0.090 * * *$ & 0.373 & $0.052 * * *$ & $0.082 * * *$ & $0.108^{* * *}$ & & & & \\
\hline & (6.044) & $(0.474)$ & $(3.317)$ & $(6.313)$ & (5.978) & & & & \\
\hline \multirow{2}{*}{$\beta$} & $0.883^{* * *}$ & $0.970^{* * *}$ & $0.885^{* * * *}$ & $0.908^{* * *}$ & 0.892 & $0.808^{* * *}$ & $0.834 * * *$ & $0.942^{* * *}$ & $0.798^{* * * *}$ \\
\hline & $(49.45)$ & (125.6) & $(47.75)$ & (75.60) & & $(19.82)$ & $(38.20)$ & (59.59) & $(66.11)$ \\
\hline \multirow[t]{2}{*}{$\gamma$} & & $0.123 *$ & $0.068 * *$ & $0.512^{* * *}$ & & & & 0.094 & $0.539 * * *$ \\
\hline & & $(1.804)$ & $(2.149)$ & (3.376) & & & & $(1.231)$ & (3.880) \\
\hline \multirow[t]{2}{*}{$\delta$} & & & & $0.567 * *$ & & & & & $0.377^{*}$ \\
\hline & & & & (2.138) & & & & & $(1.826)$ \\
\hline \multirow[t]{2}{*}{$\varphi$} & & & & & & 0.078 & 0.012 & 0.310 & 0.165 \\
\hline & & & & & & $(0.792)$ & $(0.153)$ & $(0.302)$ & $(0.297)$ \\
\hline \multirow[t]{2}{*}{$d$} & & & & & & $0.787 * * *$ & $0.899 * * *$ & $0.231^{* *}$ & $0.690^{* * * *}$ \\
\hline & & & & & & $(6.811)$ & $(11.00)$ & $(2.353)$ & \\
\hline \multirow[t]{2}{*}{$\log k$} & & & & & & & $-0.035^{* *}$ & & \\
\hline & & & & & & & $(-1.969)$ & & \\
\hline \multicolumn{10}{|c|}{ Diagnostic test } \\
\hline $\log (\mathrm{L})$ & -3015.6 & -2997.6 & -3010.2 & -2997.0 & -3020.2 & -3016.6 & -3013.7 & -2995.5 & -3016.6 \\
\hline \multirow[t]{2}{*}{$\mathrm{Q}^{2}(10)$} & 2.580 & 2.398 & 2.712 & 2.831 & 3.148 & 2.111 & 1.949 & 1.838 & 2.170 \\
\hline & {$[0.958]$} & {$[0.966]$} & {$[0.951]$} & {$[0.945]$} & {$[0.925]$} & {$[0.977]$} & {$[0.983]$} & {$[0.986]$} & {$[0.975]$} \\
\hline \multirow[t]{2}{*}{$\mathrm{ARCH}(10)$} & 0.265 & 0.239 & 0.286 & 0.290 & 0.329 & 0.209 & 0.193 & 0.180 & 0.213 \\
\hline & {$[0.988]$} & {$[0.992]$} & {$[0.984]$} & [0.984] & {$[0.974]$} & {$[0.996]$} & [0.997] & {$[0.998]$} & {$[0.975]$} \\
\hline
\end{tabular}

Notes: See Table A1. 
Table A4 Estimation results of GARCH-class models for WF4 returns

\begin{tabular}{|c|c|c|c|c|c|c|c|c|c|}
\hline & GARCH & EGARCH & GJR & APARCH & IGARCH & FIGARCH & HYGARCH & FIEGARCH & FIAPARCH \\
\hline \multicolumn{10}{|c|}{ Mean equation } \\
\hline \multirow[t]{2}{*}{$\mu$} & 0.037 & -0.005 & 0.007 & -0.008 & 0.031 & 0.027 & 0.030 & -0.012 & -0.008 \\
\hline & $(0.815)$ & $(-0.104)$ & $(0.158)$ & $(-1.433)$ & $(0.693)$ & $(0.591)$ & $(0.668)$ & $(-0.288)$ & $(-0.101)$ \\
\hline \multirow{2}{*}{$\lambda$} & $0.173^{* * *}$ & $0.177 * * *$ & $0.176^{* * *}$ & $0.169 * * *$ & $0.172 * * *$ & $0.175^{* * *}$ & $0.175^{* * *}$ & $0.176^{* * * *}$ & $0.169 * * *$ \\
\hline & (6.459) & (6.826) & (6.499) & $(46.17)$ & (6.779) & (6.966) & (6.737) & (7.220) & (6.588) \\
\hline \multicolumn{10}{|c|}{ Volatility equation } \\
\hline \multirow[t]{2}{*}{$\omega$} & $0.081 * * *$ & $1.075^{* * *}$ & $0.081 * * *$ & $0.039^{* * *}$ & $0.040^{* * *}$ & $0.054 * * *$ & $0.100 * * *$ & $-1.386^{* *}$ & $0.054 * * *$ \\
\hline & $(3.030)$ & (5.539) & (2.903) & $(4.125)$ & (3.169) & (2.714) & (2.959) & $(-2.055)$ & (2.803) \\
\hline \multirow[t]{2}{*}{$\alpha$} & $0.090^{* * *}$ & 0.280 & $0.052 * * *$ & $0.080^{* * *}$ & $0.108^{* * *}$ & & & & \\
\hline & $(5.945)$ & $(0.446)$ & $(3.280)$ & $(4.302)$ & $(5.671)$ & & & & \\
\hline \multirow{2}{*}{$\beta$} & $0.882 * * *$ & $0.970 * * *$ & $0.884 * * *$ & $0.906^{* * * *}$ & 0.892 & $0.803^{* * *}$ & $0.832 * * *$ & $0.950^{* * * *}$ & $0.769^{* * *} *$ \\
\hline & $(47.75)$ & (122.1) & (45.98) & (77.30) & & (18.44) & (35.47) & (66.97) & (33.12) \\
\hline \multirow[t]{2}{*}{$\gamma$} & & $0.134 * *$ & $0.069^{* *}$ & $0.522 * * *$ & & & & $0.128^{* *}$ & $0.546 * * *$ \\
\hline & & (2.116) & $(2.281)$ & (3.565) & & & & $(2.293)$ & (4.011) \\
\hline \multirow[t]{2}{*}{$\delta$} & & & & 0.422 & & & & & 0.294 \\
\hline & & & & $(1.212)$ & & & & & $(0.875)$ \\
\hline \multirow[t]{2}{*}{$\varphi$} & & & & & & 0.089 & 0.020 & 0.264 & 0.195 \\
\hline & & & & & & $(0.883)$ & $(0.250)$ & $(0.475)$ & $(0.772)$ \\
\hline \multirow[t]{2}{*}{$d$} & & & & & & $0.776^{* * *}$ & $0.894 * * *$ & $0.174 * * *$ & $0.626^{* * * *}$ \\
\hline & & & & & & $(6.487)$ & (10.73) & $(2.732)$ & $(5.426)$ \\
\hline \multirow[t]{2}{*}{$\log k$} & & & & & & & $-0.036^{*}$ & & \\
\hline & & & & & & & $(-1.958)$ & & \\
\hline \multicolumn{10}{|c|}{ Diagnostic test } \\
\hline $\log (\mathrm{L})$ & -2925.5 & -2907.3 & -2919.7 & -2905.2 & -2930.3 & -2926.7 & -2923.8 & -2904.9 & -2899.5 \\
\hline \multirow[t]{2}{*}{$Q^{2}(10)$} & 2.740 & 2.560 & 2.772 & 3.261 & 3.279 & 2.543 & 2.316 & 3.310 & 3.052 \\
\hline & {$[0.950]$} & {$[0.959]$} & {$[0.948]$} & {$[0.917]$} & {$[0.916]$} & {$[0.960]$} & {$[0.970]$} & {$[0.913]$} & {$[0.931]$} \\
\hline \multirow[t]{2}{*}{$\mathrm{ARCH}(10)$} & 0.281 & 0.255 & 0.290 & 0.333 & 0.338 & 0.250 & 0.228 & 0.323 & 0.298 \\
\hline & {$[0.986]$} & {$[0.990]$} & {$[0.984]$} & {$[0.972]$} & {$[0.971]$} & {$[0.991]$} & {$[0.994]$} & {$[0.975]$} & [0.982] \\
\hline
\end{tabular}

Notes: See Table A1. 


\section{Figures (color)}
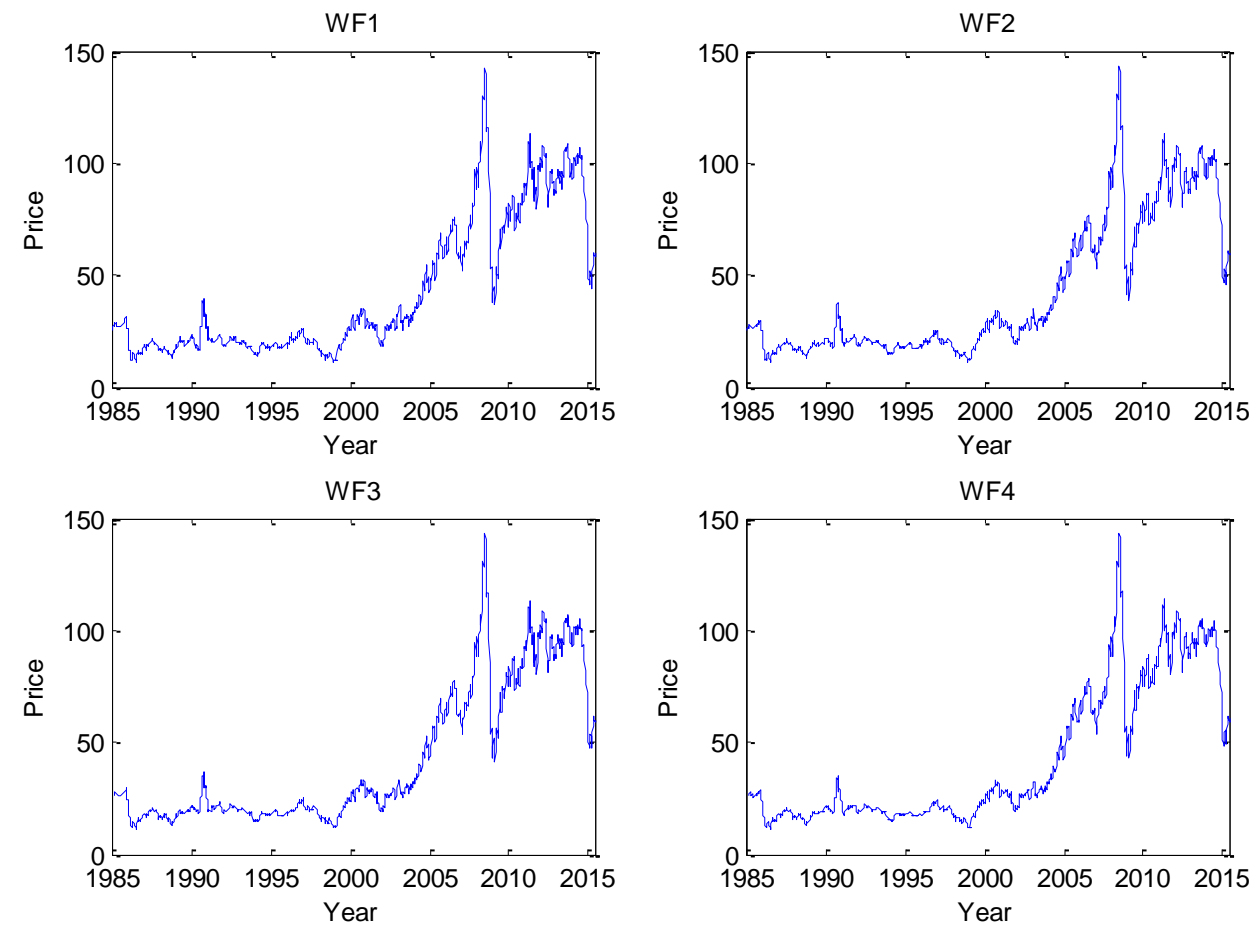

Figure 1 Crude oil futures prices over time 


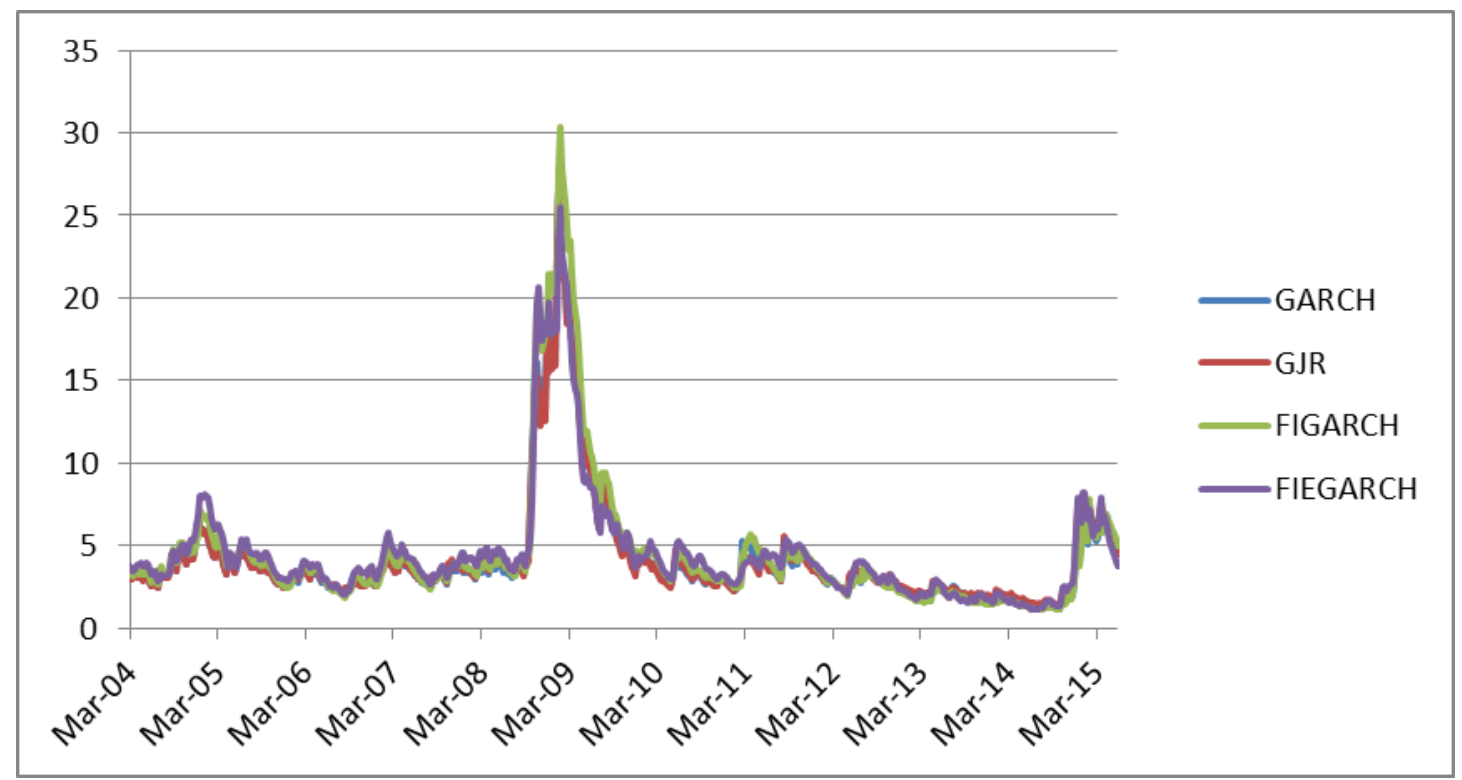

Figure 2 Volatility forecasts of WF1 returns 


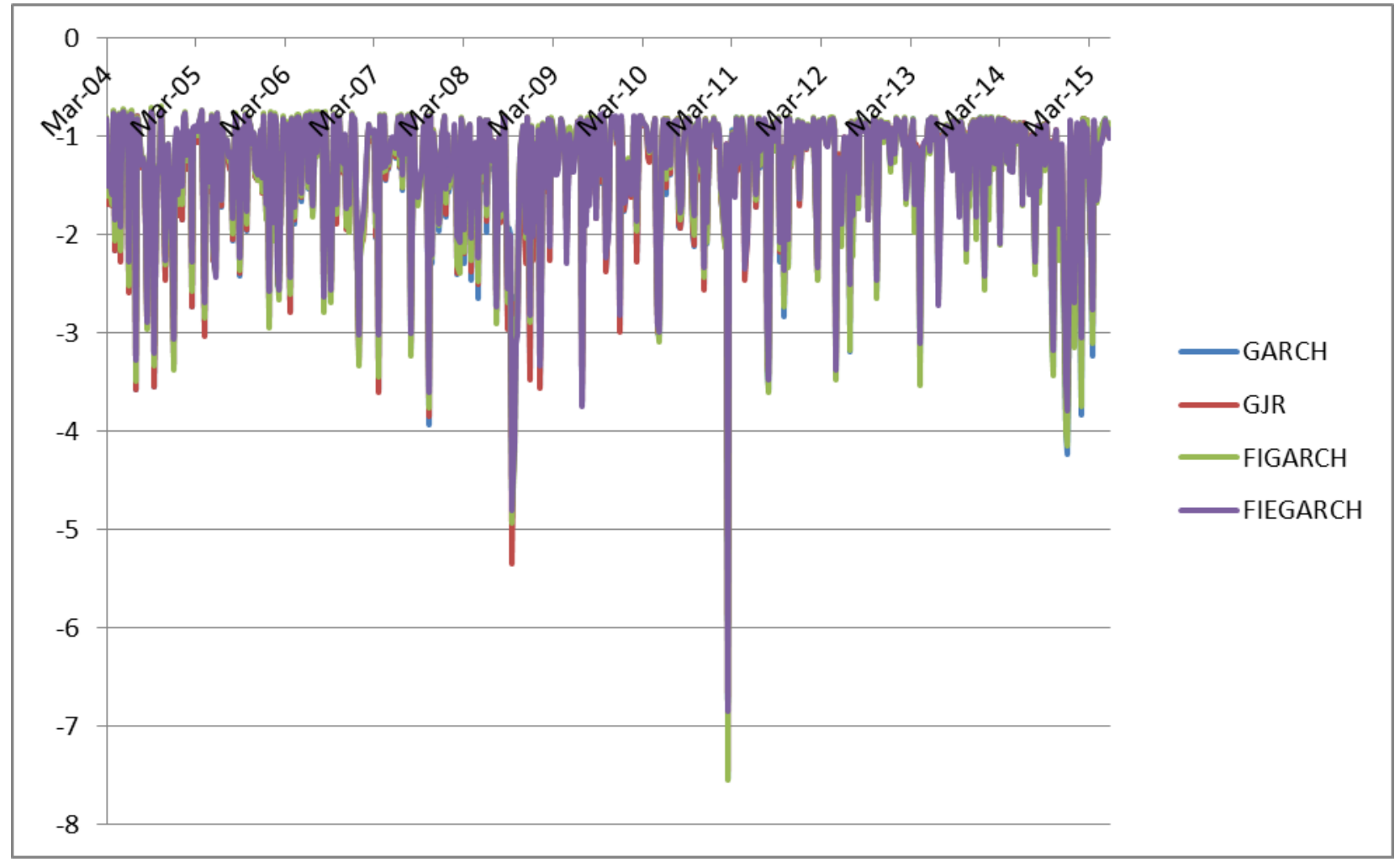

Figure 3 Density forecasts (log values) of WF1 returns 


\section{Tables}

Table 1 Descriptive statistics of excess returns of crude oil futures

\begin{tabular}{ccccc}
\hline & WF1 & WF2 & WF3 & WF4 \\
\hline Mean & 0.027 & 0.027 & 0.027 & 0.027 \\
Median & 0.104 & 0.121 & 0.119 & 0.124 \\
Maximum & 12.77 & 11.31 & 10.74 & 10.31 \\
Minimum & -9.521 & -10.491 & -9.215 & -8.711 \\
Std. Dev. & 2.072 & 1.890 & 1.778 & 1.688 \\
Skewness & -0.278 & -0.377 & -0.394 & -0.412 \\
Kurtosis & 6.502 & 6.231 & 6.122 & 6.192 \\
Jarque-Bera & $831.3^{* * *}$ & $727.9^{* * *}$ & $685.5^{* * *}$ & $718.6^{* * *}$ \\
ADF & $-35.23^{* * *}$ & $-33.95^{* * *}$ & $-33.83^{* * *}$ & $-33.81^{* * *}$ \\
PP & $-35.63^{* * *}$ & $-34.47^{* * *}$ & $-34.51^{* * *}$ & $-34.62^{* * *}$ \\
KPSS & 0.062 & 0.07 & 0.076 & 0.082 \\
Q(10) & $54.23^{* * *}$ & $68.26^{* * *}$ & $71.84^{* * *}$ & $74.86^{* * *}$ \\
Q ${ }^{2}(10)$ & $385.4^{* * *}$ & $296.0^{* * *}$ & $335.3^{* * *}$ & $370.6^{* * * *}$ \\
ARCH(10) & $19.54^{* * *}$ & $16.08^{* * *}$ & $17.57^{* * *}$ & $18.82^{* * * *}$ \\
\hline
\end{tabular}

Notes: The Jarque-Bera (1980) statistic tests for the null hypothesis of Gaussian distribution. ADF, PP and KPSS denote the statistics of Augment Dickey-Fuller (1979), Phillips-Perron (1988) and Kwiatkowski et al. (1992) unit root test, respectively. The optimal lag length of ADF test is chosen based on Schwarz information criterion (SIC) (Schwarz, 1978) and the optimal bandwidths of PP unit root test and KPSS stationarity test are determined based on Newey-West criterion (Newey and West, 1994). The null hypothesis of ADF and PP tests is a unit root and that of KPSS test is stationarity. $\mathrm{Q}(l)$ and $\mathrm{Q}^{2}(l)$ are the Ljung-Box(1978) statistics of the return and squared return series for up to the $l$ th order serial correlation, respectively. $* * *$ and $* * *$ denote rejection of the null hypothesis at $10 \%, 5 \%$ and $1 \%$ significance levels, respectively. 
Table 2 Average logarithmic scores of oil return forecasts

\begin{tabular}{ccccc}
\hline & WF1 & WF2 & WF3 & WF4 \\
\hline \multirow{2}{*}{ GARCH } & $-1.377 * * *$ & $-1.391 * * *$ & $-1.399 * * *$ & $-1.404 * * *$ \\
& $(-8.913)$ & $(-10.25)$ & $(-9.795)$ & $(-8.925)$ \\
EGARCH & $-1.351 * * *$ & $-1.370^{* * *}$ & $-1.383 * * *$ & $-1.392 * * *$ \\
& $(-8.001)$ & $(-10.39)$ & $(-10.06)$ & $(-9.249)$ \\
GJR & $-1.365 * * *$ & $-1.381 * * *$ & $-1.392 * * *$ & $-1.401 * * *$ \\
& $(7.493)$ & $(-9.220)$ & $(-8.903)$ & $(-8.174)$ \\
IGARCH & $-1.364 * * *$ & $-1.375^{* * *}$ & $-1.381 * * *$ & $-1.385 * * *$ \\
& $(-5.836)$ & $(-6.328)$ & $(-5.770)$ & $(-4.916)$ \\
APARCH & $-1.345 * * *$ & $-1.354 * * *$ & $-1.365 * * *$ & $-1.381 * * *$ \\
& $(-3.870)$ & $(-3.887)$ & $(-3.289)$ & $(-4.461)$ \\
FIGARCH & $-1.364 * * *$ & $-1.377 * * *$ & $-1.385 * * *$ & $-1.390 * * *$ \\
& $(-7.236)$ & $(-7.759)$ & $(-7.628)$ & $(-6.691)$ \\
FIEGARCH & -1.330 & -1.339 & -1.350 & -1.360 \\
& $(\mathrm{NA})$ & $(\mathrm{NA})$ & $(\mathrm{NA})$ & $(\mathrm{NA})$ \\
FIAPARCH & $-1.342 * * *$ & $-1.353 * * *$ & $-1.359 * *$ & -1.356 \\
& $(-3.776)$ & $(-3.728)$ & $(-2.045)$ & $(0.909)$ \\
HYGARCH & $-1.379 * * *$ & $-1.391 * * *$ & $-1.398 * * *$ & $-1.404 * * *$ \\
& $(-10.56)$ & $(-11.01)$ & $(-10.75)$ & $(-9.724)$ \\
\hline
\end{tabular}

Notes: This table provides the average logarithmic scores $(\ln S)$ of density forecasts. The numbers in parentheses are the t-statistics of Mitchell and Hall (2005) test. The null hypothesis is that the corresponding model and FIEGARCH have the equal predictive accuracy of return density. The asterisks $*, * *$ and $* * *$ denote the rejections of null hypothesis at $10 \%, 5 \%$ and $1 \%$ significance levels, respectively. 
Table 3 The failure ratios of GARCH models

\begin{tabular}{ccccc}
\hline & WF1 & WF2 & WF3 & WF4 \\
\hline \multirow{2}{*}{ GARCH } & $0.637^{* * *}$ & $0.598^{* * *}$ & $0.614^{* * *}$ & $0.608^{* * *}$ \\
& $(6.904)$ & $(4.836)$ & $(5.721)$ & $(5.364)$ \\
EGARCH & $0.772^{* * *}$ & $0.663^{* * *}$ & $0.719^{* * *}$ & $0.712^{* * *}$ \\
& $(15.67)$ & $(8.330)$ & $(11.79)$ & $(11.34)$ \\
GJR & $0.612^{* * *}$ & $0.581^{* * *}$ & $0.600^{* * *}$ & $0.595^{* * *}$ \\
& $(5.542)$ & $(3.970)$ & $(4.924)$ & $(4.662)$ \\
IGARCH & 0.520 & 0.514 & 0.533 & $0.542^{* *}$ \\
& $(0.949)$ & $(0.701)$ & $(1.612)$ & $(2.029)$ \\
APARCH & $0.659^{* * *}$ & $0.615 * * *$ & $0.627 * * *$ & $0.618^{* * *}$ \\
& $(8.136)$ & $(5.721)$ & $(6.352)$ & $(5.901)$ \\
FIGARCH & $0.547^{* *}$ & $0.550^{* *}$ & $0.567 * * *$ & $0.572^{* * *}$ \\
& $(2.278)$ & $(2.446)$ & $(3.287)$ & $(3.543)$ \\
FIAPARCH & $0.624 * * *$ & $0.571^{* * *}$ & $0.583^{* * *}$ & $0.542^{* *}$ \\
& $(6.171)$ & $(3.458)$ & $(4.056)$ & $(2.028)$ \\
HYGARCH & $0.654^{* * *}$ & $0.647^{* * *}$ & $0.627 * * *$ & $0.622^{* * *}$ \\
& $(7.841)$ & $(7.466)$ & $(6.352)$ & $(6.080)$ \\
\hline
\end{tabular}

Notes: This table shows the ratio of weeks that each model fails to beat the benchmark of FIEGARCH model in forecasting density. The numbers in parentheses are the t-statistics for testing the null hypothesis that the failure ratio is equal to 0.5 . The asterisks $* * *$ and $* * *$ denote the rejections of null hypothesis at $10 \%, 5 \%$ and $1 \%$ significance levels, respectively. 
Table 4 Independence for occurrence of the failure of each model in beating HV

\begin{tabular}{|c|c|c|c|c|c|c|c|c|}
\hline & \multicolumn{4}{|c|}{$m=3$} & \multicolumn{4}{|c|}{$m=6$} \\
\hline & WF1 & WF2 & WF3 & WF4 & WF1 & WF2 & WF3 & WF4 \\
\hline GARCH & $0.0756^{* * *}$ & $0.0397 * * *$ & $0.0262 * * *$ & $0.0160 * * *$ & $0.0693 * * *$ & $0.0338 * * *$ & $0.0175^{* * *} *$ & $0.0103 * * *$ \\
\hline EGARCH & $0.1125^{* * *} *$ & $0.0276^{* * *} *$ & $0.0410 * * *$ & $0.0372 * * *$ & $0.1329 * * *$ & $0.0195 * * *$ & 0.0357 *** & $0.0330 * * *$ \\
\hline GJR & $0.0670 * * *$ & $0.0457 * * *$ & $0.0312 * * *$ & $0.0177^{* * *} *$ & $0.0587 * * *$ & $0.0353 * * *$ & $0.0207 * * *$ & $0.0121 * * *$ \\
\hline IGARCH & $0.0068 * * *$ & 0.0057 **** & $0.0015^{* * *}$ & $0.0005^{* * * *}$ & $0.0058^{* * *}$ & $0.0043^{* * *}$ & $0.0014 * * *$ & $0.0004 * * *$ \\
\hline APARCH & $0.0729 * * *$ & $0.0251 * * *$ & $0.0138 * * *$ & $0.0033 * *$ & $0.0527 * * *$ & $0.0165^{* * *} *$ & $0.0106^{* * * *}$ & $0.0012 *$ \\
\hline FIGARCH & $0.0238 * * *$ & $0.0198 * * *$ & $0.0056 * * *$ & $0.0039 * * *$ & $0.0174 * * *$ & $0.0121 * * *$ & $0.0043 * * *$ & $0.0027 * * *$ \\
\hline FIAPARCH & $0.0618 * * *$ & $0.0170^{* * * *}$ & $0.0065^{* * *}$ & $0.0031^{* * *}$ & $0.0487^{* * *}$ & $0.0107 * * *$ & $0.0030^{* * *}$ & $0.0013 * * *$ \\
\hline HYGARCH & $0.0902 * * *$ & $0.0657 * * *$ & $0.0365 * * *$ & $0.0018^{* * *} *$ & $0.0883 * * *$ & $0.0672 * * *$ & $0.0262 * * *$ & $0.0125^{* * * *}$ \\
\hline
\end{tabular}

Notes: This table provides the BDS statistics of Broock et al.(1996) test for the serial independence. We test the independence for occurrence of the failure of each model in beating FIEGARCH. The null hypothesis is that the series is independent against the unknown dependence. We report the results for the embedding dimensions $\mathrm{m}=3$ and $\mathrm{m}=6$. The asterisks *, $* *$ and $* * *$ denote the rejections of null hypothesis at $10 \%, 5 \%$ and $1 \%$ significance levels, respectively. 
Table 5 Performances of GARCH-based strategies for weekly balancing frequency

\begin{tabular}{|c|c|c|c|c|c|c|c|c|}
\hline & \multicolumn{4}{|c|}{ Sharpe ratio } & \multicolumn{4}{|c|}{ Certainty equivalent return } \\
\hline & WF1 & WF2 & WF3 & WF4 & WF1 & WF2 & WF3 & WF4 \\
\hline \multicolumn{9}{|c|}{ Panel A: Portfolio performance for $\gamma=3$} \\
\hline GARCH & $1.038 * * *$ & $1.003 * * *$ & $1.013 * * *$ & $1.052 * * *$ & 18.74 & 19.34 & 19.49 & 20.14 \\
\hline EGARCH & $1.029 * * *$ & $1.013 * * *$ & $1.028 * * *$ & $1.061 * * *$ & 18.47 & 19.39 & 19.74 & 20.39 \\
\hline GJR & $1.027 * * *$ & $0.997 * * *$ & $1.007 * * *$ & $1.045^{* * *}$ & 18.53 & 19.20 & 19.36 & 20.00 \\
\hline IGARCH & $1.034 * * *$ & $0.997 * * *$ & $1.006^{* * *}$ & $1.039 * * *$ & 18.19 & 18.81 & 19.02 & 19.56 \\
\hline APARCH & $1.021 * * *$ & $1.006^{* * *}$ & $1.027 * * *$ & $1.058 * * *$ & 18.28 & 19.12 & 19.52 & 20.08 \\
\hline FIGARCH & $1.066 * * *$ & $1.029 * * *$ & $1.018 * * *$ & $1.055^{* * *}$ & 18.90 & 19.44 & 19.24 & 19.86 \\
\hline FIEGARCH & $1.059 * * *$ & $1.034 * * *$ & $1.032 * * *$ & $1.065^{* * *}$ & 18.59 & 19.34 & 19.35 & 19.97 \\
\hline FIAPARCH & $1.049 * * *$ & $1.010 * * *$ & $1.030 * * *$ & $1.062 * * *$ & 18.71 & 19.13 & 19.43 & 20.01 \\
\hline HYGARCH & $1.064 * * *$ & $1.024 * * *$ & $1.024 * * *$ & $1.063 * * *$ & 19.21 & 19.64 & 19.60 & 20.27 \\
\hline \multicolumn{9}{|c|}{ Panel B: Portfolio performance for $\gamma=6$} \\
\hline GARCH & $1.161 * * *$ & $1.171 * * *$ & $1.202 * * *$ & $1.217 * * *$ & 15.95 & 16.74 & 16.94 & 16.98 \\
\hline EGARCH & $1.072 * * *$ & $1.140 * * *$ & $1.174 * * *$ & $1.202 * * *$ & 15.20 & 16.42 & 16.72 & 16.97 \\
\hline GJR & $1.135 * * *$ & $1.145^{* * *}$ & $1.179 * * *$ & $1.196 * * *$ & 15.68 & 16.40 & 16.64 & 16.70 \\
\hline IGARCH & $1.160 * * *$ & $1.175^{* * *}$ & $1.185 * * *$ & $1.202 * * *$ & 15.64 & 16.46 & 16.39 & 16.43 \\
\hline APARCH & $1.133 * * *$ & $1.164 * * *$ & $1.176^{* * *}$ & $1.193 * * *$ & 15.53 & 16.44 & 16.47 & 16.57 \\
\hline FIGARCH & $1.097 * * *$ & $1.190 * * *$ & $1.214 * * *$ & $1.225 * * *$ & 15.49 & 16.87 & 16.98 & 16.97 \\
\hline FIEGARCH & $1.079 * * *$ & $1.157 * * *$ & $1.197 * * *$ & $1.224 * * *$ & 15.08 & 16.27 & 16.56 & 16.76 \\
\hline FIAPARCH & $1.108 * * *$ & $1.166^{* * * *}$ & $1.158 * * *$ & $1.209 * * *$ & 15.47 & 16.53 & 16.25 & 16.63 \\
\hline HYGARCH & $1.076^{* * *}$ & $1.175^{* * *}$ & $1.214 * * *$ & $1.230 * * *$ & 15.47 & 16.95 & 17.26 & 17.28 \\
\hline
\end{tabular}

Notes: This table provides the gains of Sharpe ratio and certainty equivalent return of related portfolios over the benchmark portfolio with 50\% oil futures and 50\% Treasury bill. We use the method suggested by Jobson and Korkie (1981) after making the correction pointed out in Memmel (2003) to test whether the Sharpe ratios of each GARCH strategy and the benchmark strategy are statistically distinguishable. The asterisk $*, * *$ and $* * *$ denote the rejection of null hypothesis of equal Sharpe ratio at 10\%, 5\% and $1 \%$ significance levels, respectively. 
Table 6 Performances of GARCH-based strategies for monthly balancing frequency

\begin{tabular}{ccccc}
\hline & \multicolumn{2}{c}{ Sharpe ratio } & \multicolumn{2}{c}{ Certainty equivalent return } \\
\cline { 2 - 5 } & $\gamma=3$ & $\gamma=6$ & $\gamma=3$ & $\gamma=6$ \\
\hline GARCH & $0.900^{* *}$ & $0.967^{*}$ & 16.18 & 15.91 \\
EGARCH & $0.799^{*}$ & $0.900^{*}$ & 14.80 & 15.23 \\
GJR & $0.889^{* *}$ & $0.956^{*}$ & 15.95 & 15.71 \\
IGARCH & $0.921^{*}$ & $0.985^{*}$ & 15.56 & 15.74 \\
APARCH & $0.869^{*}$ & $0.947^{*}$ & 15.63 & 15.62 \\
FIGARCH & $0.857^{*}$ & $0.940^{*}$ & 15.84 & 15.23 \\
FIEGARCH & $0.853^{*}$ & $0.911^{*}$ & 15.33 & 15.17 \\
FIAPARCH & $0.951^{* *}$ & $1.009^{* *}$ & 16.64 & 16.45 \\
HYGARCH & $0.939^{* *}$ & $0.988^{*}$ & 16.81 & 16.14 \\
\hline
\end{tabular}

Notes: See Table 5 